\title{
Comparison between 3D-Var and 4D-Var data assimilation methods for the simulation of a heavy rainfall case in central Italy
}

\author{
Vincenzo Mazzarella $^{1,2}$, Ida Maiello ${ }^{3,2}$, Vincenzo Capozzi ${ }^{1}$, Giorgio Budillon ${ }^{1}$, and Rossella Ferretti ${ }^{2}$ \\ ${ }^{1}$ Department of Science and Technology, University of Naples "Parthenope", Naples, Italy \\ ${ }^{2}$ Centre of Excellence CETEMPS, Department of Physical and Chemical Sciences, \\ University of L'Aquila, L'Aquila, Italy \\ ${ }^{3}$ Department of Information Engineering, Electronics and Telecommunications, Sapienza University \\ of Rome, Rome, Italy
}

Correspondence to: Vincenzo Mazzarella (vincenzo.mazzarella@uniparthenope.it)

Received: 12 January 2017 - Revised: 28 June 2017 - Accepted: 11 July 2017 - Published: 11 August 2017

\begin{abstract}
This work aims to provide a comparison between three dimensional and four dimensional variational data assimilation methods (3D-Var and 4D-Var) for a heavy rainfall case in central Italy. To evaluate the impact of the assimilation of reflectivity and radial velocity acquired from Monte Midia Doppler radar into the Weather Research Forecasting (WRF) model, the quantitative precipitation forecast (QPF) is used.

The two methods are compared for a heavy rainfall event that occurred in central Italy on 14 September 2012 during the first Special Observation Period (SOP1) of the HyMeX (HYdrological cycle in Mediterranean EXperiment) campaign. This event, characterized by a deep low pressure system over the Tyrrhenian Sea, produced flash floods over the Marche and Abruzzo regions, where rainfall maxima reached more than $150 \mathrm{~mm} 24 \mathrm{~h}^{-1}$.

To identify the best QPF, nine experiments are performed using 3D-Var and 4D-Var data assimilation techniques. All simulations are compared in terms of rainfall forecast and precipitation measured by the gauges through three statistical indicators: probability of detection (POD), critical success index (CSI) and false alarm ratio (FAR). The assimilation of conventional observations with 4D-Var method improves the QPF compared to 3D-Var. In addition, the use of radar measurements in $4 \mathrm{D}$-Var simulations enhances the performances of statistical scores for higher rainfall thresholds.
\end{abstract}

\section{Introduction}

The aim of the modern data assimilation systems is to provide the best estimate of the initial conditions, a requirement for an accurate weather forecast, through the use of huge amount of data acquired in situ or by remote-sensing. In the last years, the classical assimilation schemes, such as optimum interpolation (OI) or successive correction method (SCM), have been replaced by modern techniques with variational approach, i.e. three dimensional and four-dimensional variational data assimilation methods (3D-Var and 4D-Var). Both methods are implemented in the Weather Research Forecasting (WRF) model (Skamarock et al., 2008). In the WRF 3D-Var system (Barker et al., 2004), the observations are collected at analysis time and no model integration is required. Therefore, analysis increment does not evolve in time and consequently less computational resources are necessary. In the WRF 4D-Var system (Huang et al., 2009), an extension of 3D-Var system, the observations are incorporated at the exact time of measurement, within the assimilation window. The use of tangent linear and adjoint models (Errico, 1997; Errico et al., 1993; Erico and Reader, 1999) produces the propagation of analysis increment over the assimilation window and greater computational resources compared to 3D-Var are needed. In addition, the WRF 4D-Var system uses physical and dynamical constraints to enhance the balance of analysis field producing initial conditions that contain convective-scale balance, these constrains are not used 
(a)

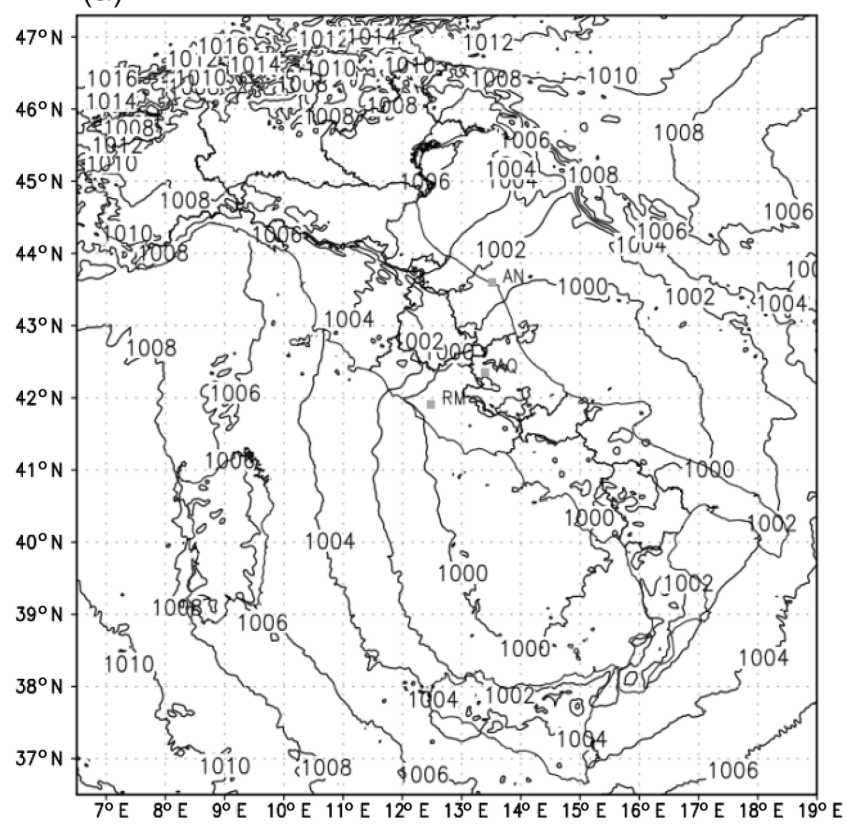

(b)

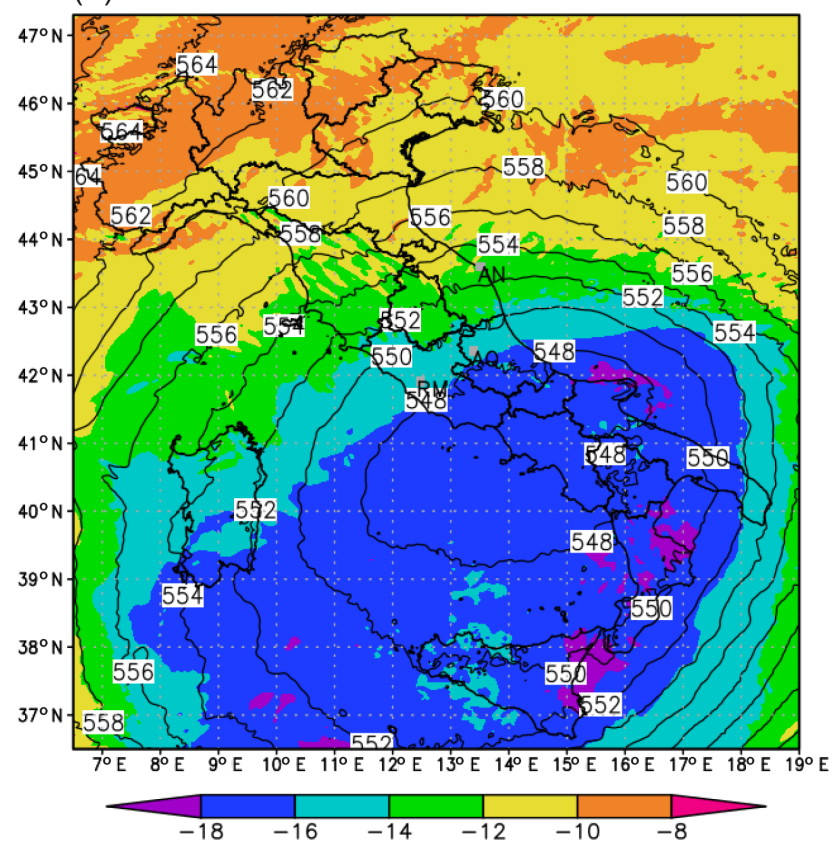

Figure 1. In (a) the surface pressure (hPa) on 14 September 2012 (12:00 UTC) is shown. In (b) temperature $\left({ }^{\circ} \mathrm{C}\right)$ and geopotential height (dam) at $500 \mathrm{hPa}$ are presented. The maps have been elaborated considering the ECMWF initial conditions.

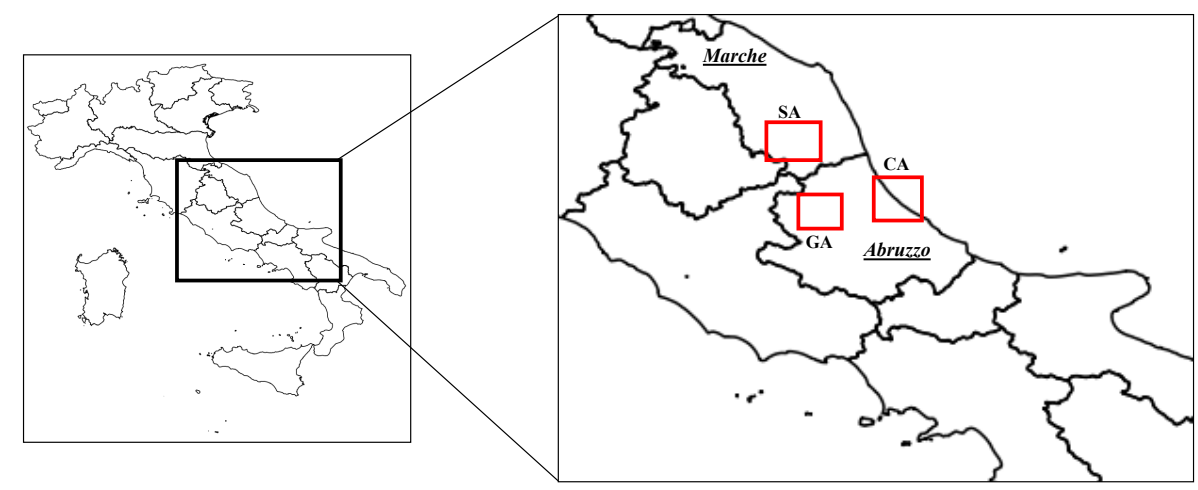

Figure 2. Location of the three specific areas with significant rainfall in $24 \mathrm{~h}$, Gran Sasso area (GA), Monti Sibillini area (SA) and CentralNorthern Abruzzo coast (CA) respectively.

in 3D-Var. This ability makes the 4D-Var technique together with a hybrid of variational method and Ensemble Kalman Filter a promising method for the future improvements of NWP (Sun et al., 2014). However, both methods determine the best estimate of the atmospheric state at analysis time, through the minimization of a cost function, which reduces the gap between observations and the trajectory forecasted by the model.

The variational techniques allow the assimilation not only of conventional observations, available from the Global Telecommunication System (GTS), but also of nonconventional observations such as radar data (Barker et al., 2004; Xiao et al., 2005, Wang et al., 2013; Hu et al., 2006;
Maiello et al., 2014) through the use of reflectivity and radial velocity operators (Sun and Crook, 1997), included in the cost function.

Chu et al. (2013) performed a comparison between 4DVar and 3D-Var methods for the forecast of two Antarctic cyclones over the Ross Sea, assimilating only conventional observations. The 4D-Var showed a better performance after the first $24 \mathrm{~h}$ of forecast. Sun and Wang (2013) also compared 4D-Var and 3D-Var for a squall line event over the US Great Plains. The results suggested that the assimilation of radial velocity and reflectivity with 4D-Var system improved the QPF skills for a short range forecast. 


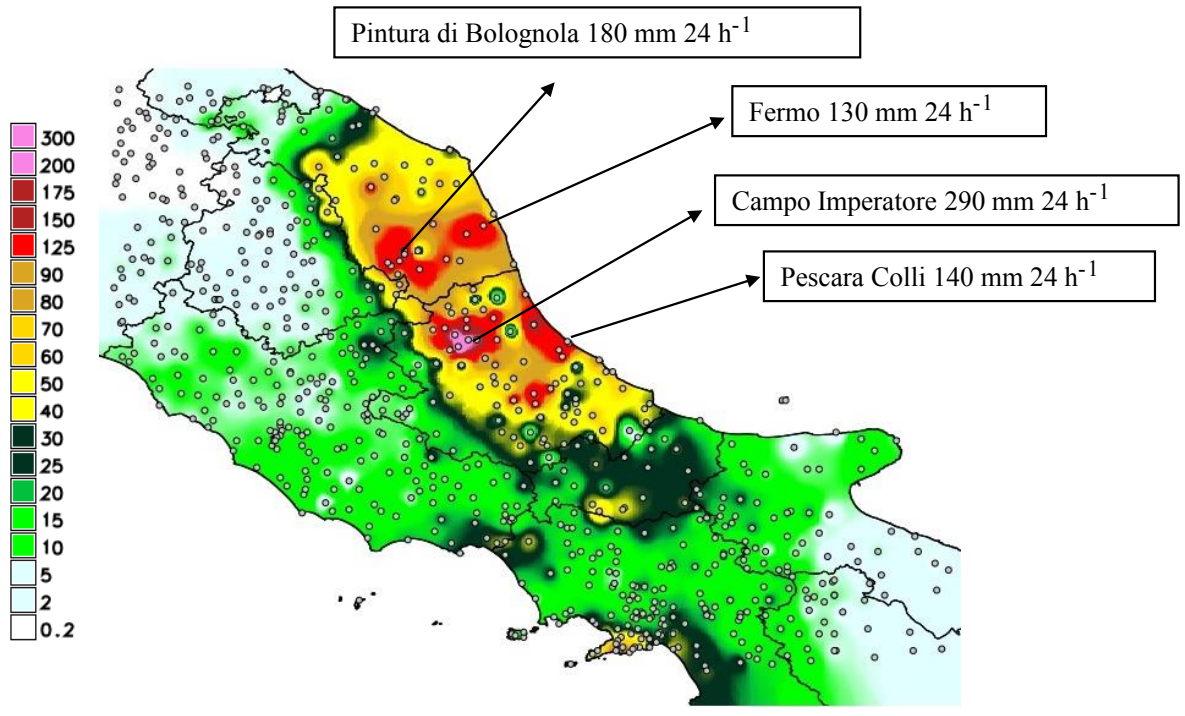

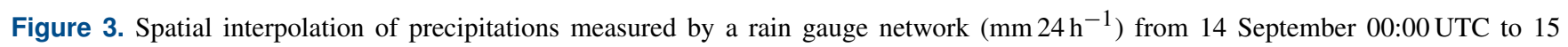
September 00:00 UTC. The rain gauge stations (dots) with significant precipitation amounts are highlighted by black arrows.

The aim of this work is to provide a preliminary comparison between 3D-Var and 4D-Var methods for a flash flood event in central Italy. The manuscript is organized as follows. Section 2 provides an overview of the case study. Section 3 presents a brief description of 3D-Var and 4D-Var experiments carried out. Quantitative precipitation forecasts (QPF) are shown and evaluated in Sect. 4. Conclusions and further developments are given in the last section.

\section{Description of the case study}

The HyMeX project aims to better understand the hydrological cycle and related processes in the Mediterranean basin, in particular the impact of extreme weather events and climate change effects on temperatures and precipitations by monitoring and modeling the ocean atmosphere coupled system. The first Special Observation Period field campaign (SOP1, Ducrocq et al., 2014) of the HyMeX project, taken place between September and November 2012, has been focused on heavy rainfall and flash floods over the Western Mediterranean area. During this campaign, twenty Intensive Observation Periods (IOPs) have been investigated and ten of them occurred in Italy.

The IOP4 occurred on 14 September 2012 and it was characterized by convective activity with a large amount of precipitation in a few hours over central Italy. A low predictability characterized this event in the estimate and localization of peak precipitation (Ferretti et al., 2014), this is the reason for choosing this study. In the morning of 14 September, a deep low pressure system over the Tyrrhenian Sea (Fig. 1) caused heavy precipitation in central Italy, mainly along the Adriatic coast of the Marche and Abruzzo regions. The interaction between cool Bora winds and warm moist
Sirocco winds over the Adriatic Sea produced persistent convective precipitation, especially in three distinct zones: Gran Sasso area (GA), Monti Sibillini area (SA) and CentralNorthern Abruzzo coast (AC) with significant rainfall in $24 \mathrm{~h}$ (Fig. 2). The low-pressure system slowly moved southeastward, dissipating its energy only in the evening of 15 September. The southeasterly wind caused several floods in coastal areas, damage to buildings, infrastructures and overflowing of many rivers. Rain gauge stations in the Marche and Abruzzo regions (Fig. 3) recorded significant rainfall during the event: Fermo $\left(130 \mathrm{~mm} 24 \mathrm{~h}^{-1}\right)$, Pescara Colli

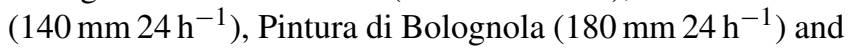

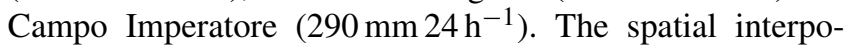
lation of $24 \mathrm{~h}$ observed precipitations from 14 September 00:00 UTC to 15 September 00:00 UTC is shown in Fig. 3.

\section{Description of the experiments}

The Advanced Research Weather Research and Forecasting Model (WRF-ARW) Version 3.7.1, is used for this study. A one-way nesting (ndown) configuration with two domains is applied. The mother domain (D01), with a spatial resolution of $12 \mathrm{~km}$, covers a large part of Mediterranean basin and Central Europe; whereas the high resolution domain (D02) with a grid space of $3 \mathrm{~km}$ includes the Italian peninsula. 37 terrain-following vertical levels from the surface up to $100 \mathrm{hPa}$ are used for both domains. The microphysics is parameterized with New Thompson scheme (Thompson et al., 2008), whereas the convective processes, although parameterized with Kain-Fritsch (Kain, 2004) scheme in D01, are explicitly solved in the inner domain. The Mellor-Yamada 2.5 turbulence scheme is used for the planetary boundary 

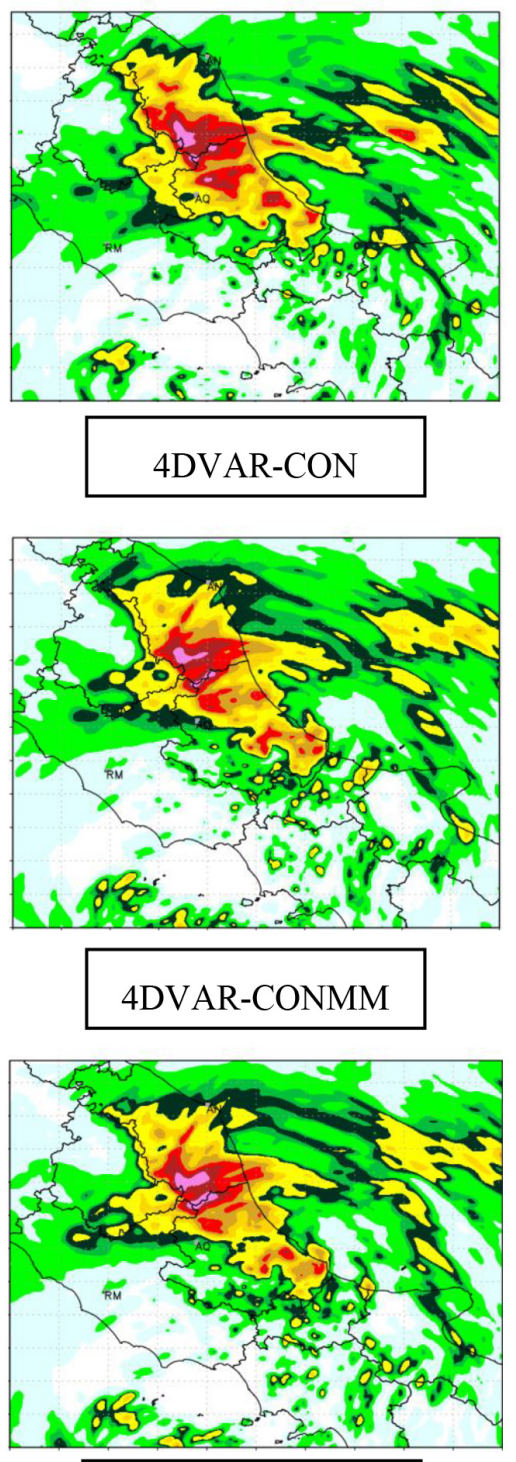

4DVAR-RVE
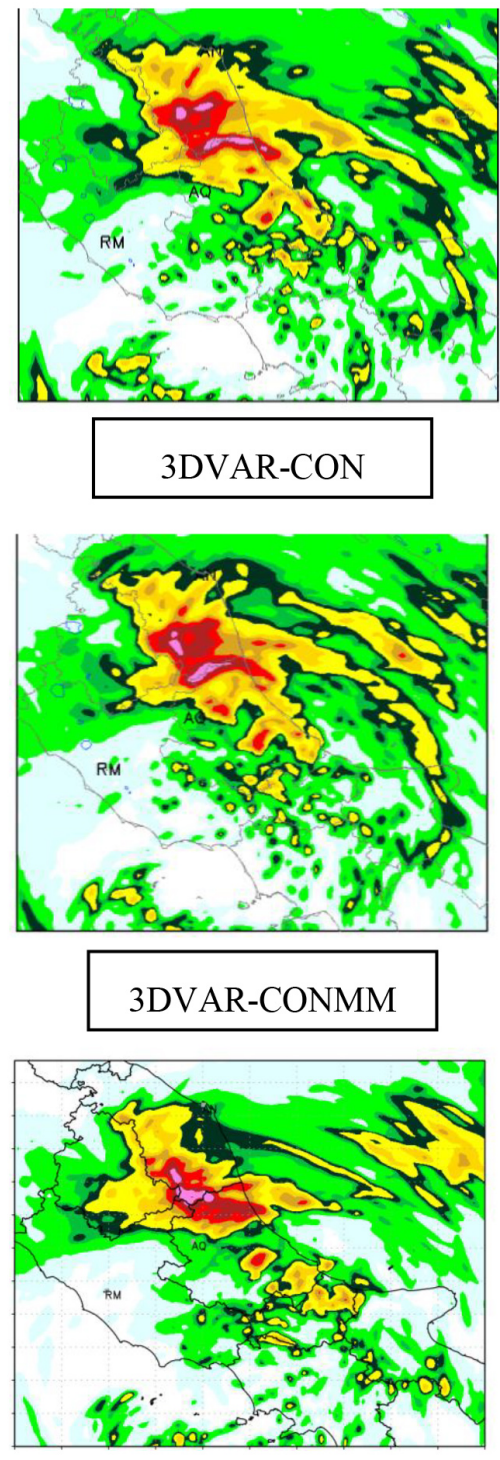

4DVAR-RRF
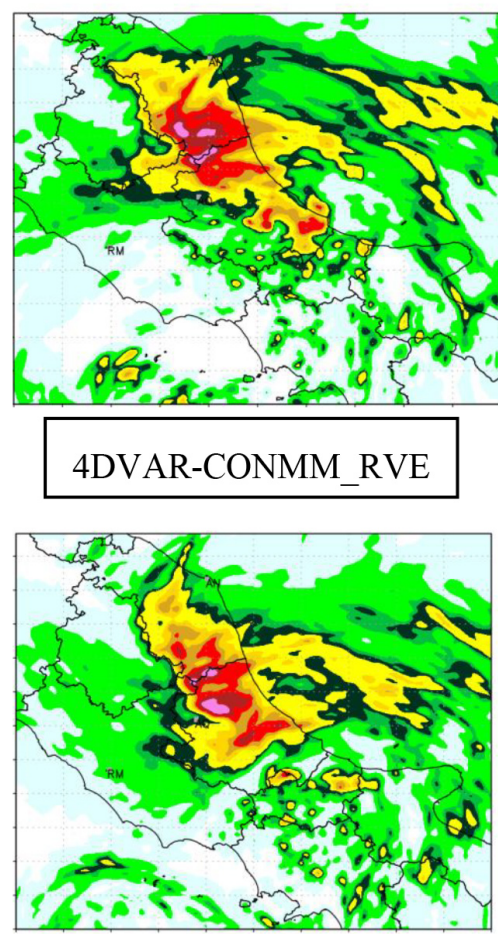

4DVAR-CONMM_RRF

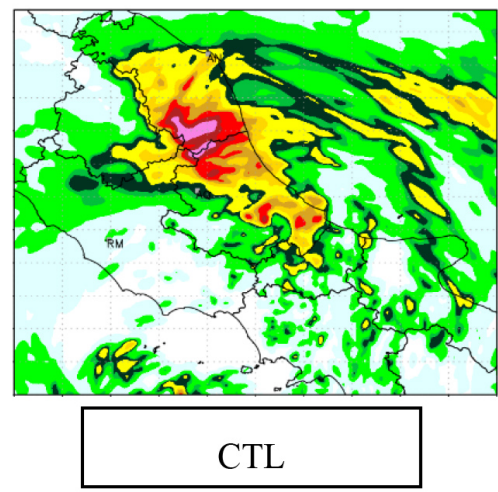

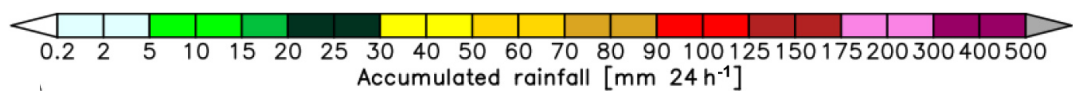

Figure 4. $24 \mathrm{~h}$ forecast precipitation at 00:00 UTC, 15 September 2012 estimated by WRF experiments. The latter acronyms are indicated in the black border rectangles.

layer (PBL) parameterization (Janjic, 2002; Mellor and Yamada, 1982).

The initialization time is 13 September 12:00 UTC for D01 domain and 14 September 00:00 UTC for D02 domain. The D01 is initialized using boundary and initial conditions (horizontal resolution of $0.25^{\circ}$ ) provided by the European Centre for Medium-Range Weather Forecasts (ECMWF), whereas D02 is initialized using boundary and initial conditions from the mother domain. In D02, both SYNOP and TEMP (hereafter referred to as conventional observations) from the GTS of the World Meteorological Organization (WMO) and Monte Midia radar data provided by the Centro Funzionale of Abruzzo region are assimilated. Monte Midia radar is a C-band Doppler radar installed on the top of Monte Midia $\left(42.0577^{\circ} \mathrm{N}, 13.1772^{\circ} \mathrm{E}, 1760 \mathrm{~m}\right.$ a.s.l.) that is located in Abruzzo region. The instrument performs a complete scan in $15 \mathrm{~min}$ with a nominal maximum range of $240 \mathrm{~km}$. Radar reflectivity and radar velocity have been processed through a quality control chain to improve the quality of measurements, before being ingested into the assimilation procedure. 
Table 1. Brief description of the experiments carried out.

\begin{tabular}{lllll}
\hline Experiment name & $\begin{array}{l}\text { Assimilation } \\
\text { technique }\end{array}$ & $\begin{array}{l}\text { Radial } \\
\text { velocity }\end{array}$ & $\begin{array}{l}\text { Radar } \\
\text { reflectivity }\end{array}$ & $\begin{array}{l}\text { Conventional } \\
\text { observations }\end{array}$ \\
\hline CTL & Nothing & No & No & No \\
3DVAR-CON & 3D-Var & No & No & Yes \\
3DVAR-CONMM & 3D-Var & Yes & Yes & Yes \\
4DVAR-CON & 4D-Var & No & No & Yes \\
4DVAR-CONMM & 4D-Var & Yes & Yes & Yes \\
4DVAR-CONMM_RRF & 4D-Var & No & Yes & Yes \\
4DVAR-CONMM_RVE & 4D-Var & Yes & No & Yes \\
4DVAR-RVE & 4D-Var & Yes & No & No \\
4DVAR-RRF & 4D-Var & No & Yes & No \\
\hline
\end{tabular}
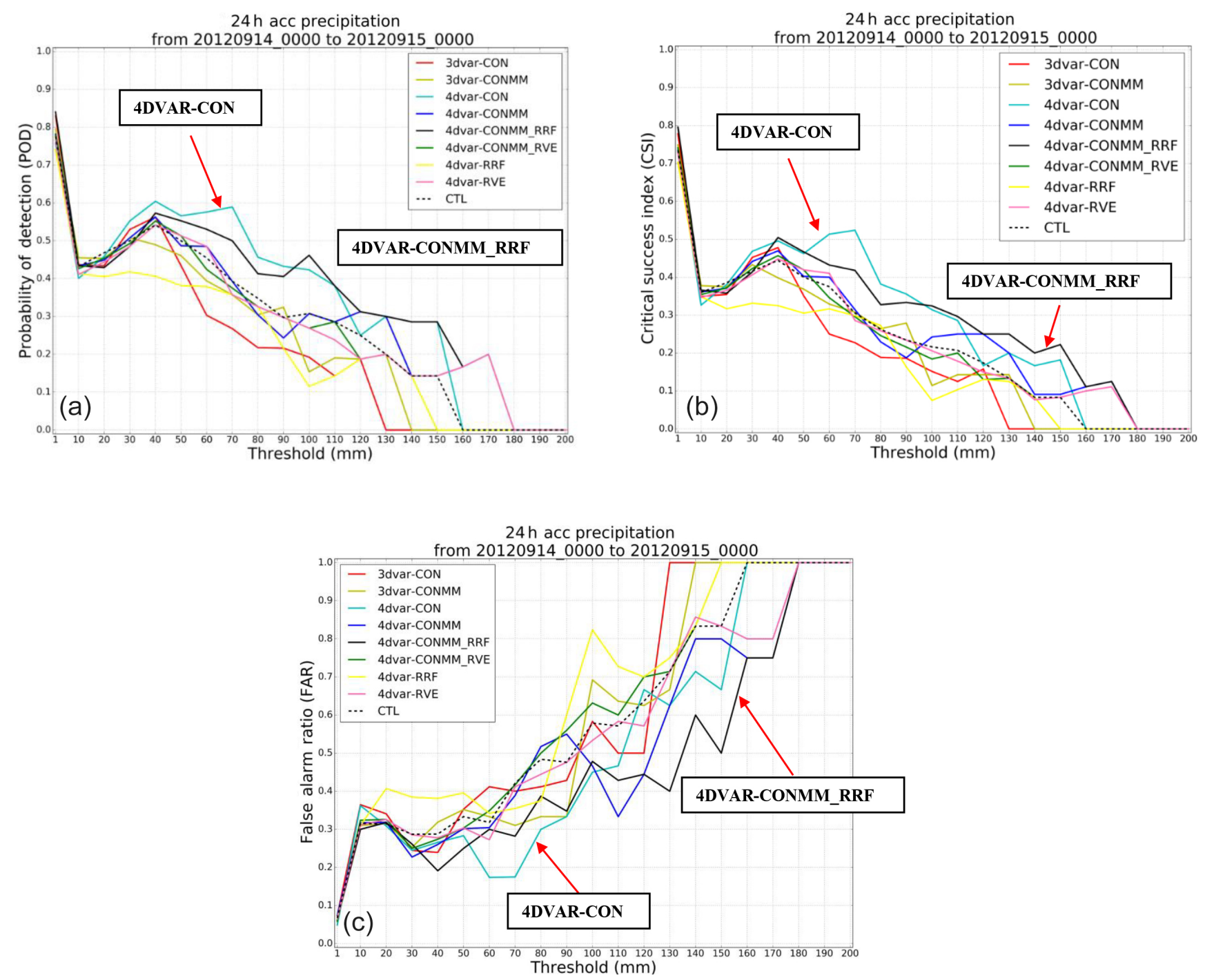

Figure 5. Probability of detection (a), Critical Success Index (b) and False Alarm Ratio (c) calculated for the nine experiments as a function of thresholds. 4DVAR-CON and 4DVAR_CONMM_RRF simulations (highlighted with a red arrow) show the best values in terms of POD,

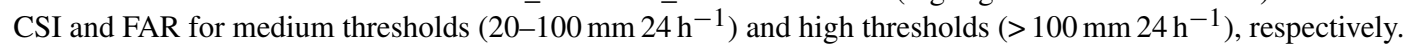


In order to minimize the effect of partial beam blocking, the compensation method proposed by Fulton et al. (1998) has been adopted. On the contrary, the beam attenuation along the path has been mitigated through the two way path integrated attenuation (PIA) technique (Picciotti et al., 2006).

In the 3D-Var experiments, the assimilation window for conventional observations is set to $\pm 1 \mathrm{~h}$ from the "time_analysis", whereas for radar data is set to $\pm 5 \mathrm{~min}$. However only data at the time_analysis, 14 September 2012 00:00 UTC, have been taken into account and assimilated. On the other hand, in the 4D-Var, a greater number of data than 3D-Var has been assimilated, since a time window of $1 \mathrm{~h}$ with sub-windows of $30 \mathrm{~min}$ has been used. More specifically, conventional observations have been assimilated at 00:00 and 01:00 UTC, whereas radar reflectivity and radial velocity every $30 \mathrm{~min}$ from 00:00 to 01:00 UTC. The limited length of the assimilation window is due to the high computational costs required to resolve tangent linear and adjoint models. However, in 3D-Var experiments the data are assimilated only at 00:00 UTC 14 September 2012, consequently the number of measurements is not the same because the same stations are assimilated more frequently using 4D-Var than 3D-Var.

According to domain dimensions, 304 conventional observations (300 SYNOP and 4 TEMP) have been assimilated every hour. The high spatial resolution of radar implies a great data availability; therefore 172800 observations have been assimilated every $30 \mathrm{~min}$ in 4D-Var experiments and only at 00:00 UTC in 3D-Var experiment. Each of observations consist of 4 reflectivity and 4 radial velocity measurements collected at different antenna elevation angles, 0, 1, 2 and $3^{\circ}$. In conclusion, the total amount of radar measurements in 3D-Var experiment, including both reflectivity and radial velocity, comprises 1382400 values. By contrast, in 4D-Var simulations, the number of radar measurements is significantly higher (5 529600 values). Another substantial difference between radar and conventional observations is related to the different spatial distribution, Monte Midia radar covers a range limited to $240 \mathrm{~km}$, whereas SYNOP and TEMP data are not uniformly distributed over the whole domain. A total of nine experiments are carried out to evaluate the performances of 3D-Var and 4D-Var methods in terms of QPF. A brief description of the simulations is provided in Table 1.

\section{Results}

The $24 \mathrm{~h}$ accumulated precipitation over central Italy, estimated by WRF simulations (Fig. 4), has been compared to the rain gauge data in Fig. 3. All experiments, except 4DVAR-CONMM_RRF, produce an overestimation of precipitation in SA. The latter, located over the Umbria-Marche Apennines, is characterized by the presence of mountains with elevation higher than $2000 \mathrm{~m}$, particularly exposed to the eastern winds and consequently to the Stau effect. These features make the QPF particularly tricky. However, the data assimilation with 3D-Var and 4D-Var methods determines a reduction in rainfall amount compared to CTL experiment and a shift in precipitation patterns. On the other hand, 4DVAR-CONMM_RRF, performed using conventional observations and radar reflectivity, produces a southward shift of precipitation pattern and, consequently, an overestimation of precipitation over GA and an underestimation over SA. 4DVAR-CON simulation, performed using only conventional observations, leads to an improvement of rainfall forecast over GA, instead. Finally, no experiments, including CTL, provide an accurate QPF along CA. The observed rainfall peaks are the result of intense convective phenomena, occurred over a restricted area and in a very short time lapse, for which WRF model fails in capturing the small-scale rainfall variability and the effect of data assimilation is not ideal (Liu et al., 2013). We can speculate that to capture such smallscale simulation at higher resolution than $3 \mathrm{~km}$ are necessary, this will be investigated in a future study.

In order to compare the numerical experiments, three statistical indicators (Wilks, 2006), critical success index (CSI), false alarm ratio (FAR) and probability of detection (POD) are evaluated using the Model Evaluation Tools (MET) verification package (Brown et al., 2009). A brief description of statistical indexes is presented below:

- POD represents the fraction of events correctly forecast. The best value is 1 .

- FAR shows the ratio of failures. A perfect forecast has $\mathrm{FAR}=0$.

- CSI combines CSI and POD, measuring the fraction of events (observed and forecasted) correctly predicted. The best value is 1 .

The scores have been calculated from a 2-by-2 contingency table, that allows for an objective comparison between rain gauge observations and rainfall forecast for the following threshold values: $1,10,20,30,40,50,60,70,80,90,100$, $110,120,130,140,150,160,170,180,190,200$. The presence of isolated rainfall peaks in the distribution of precipitation and the consequent reduction of rainfall data

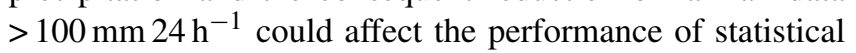
analysis. The evolution of the three statistical scores for each experiment is reported in Fig. 5.

4DVAR-CON simulation shows an improvement in terms of POD and CSI compared to 3DVAR-CON. The differences between the two experiments increase with increasing threshold values for both statistical scores. This behaviour points out the capability of 4DVAR-CON to improve the estimate of rainfall peaks, especially over GA.

The assimilation of radar data reduces the gap between 4D-Var and 3D-Var simulations at low and intermediate thresholds in terms of POD, FAR and CSI. However, the difference tends to increase and became relevant for heavy rainfalls, as shown in 4DVAR-CONMM and 3DVAR-CONMM. 
4DVAR-CONMM_RRF simulation also displays, for thresholds greater than $100 \mathrm{~mm} 24 \mathrm{~h}^{-1}$, highest values of CSI and POD respect to 3D-Var and 4D-Var experiments without radar data, highlighting the benefit of 4D-Var.

\section{Conclusions}

The goal of this study is to evaluate the impact of radar data and conventional observations assimilation using 3DVar and 4D-Var techniques. To pursue this aim, nine simulations are carried out for a heavy rainfall event occurred in central Italy on 14 September 2012. Preliminary results suggest that 4DVAR-CON experiment with conventional observations produces an improvement in terms of CSI and POD compared to 3DVAR-CON experiment. More precisely, the statistical indexes, relatively to 4DVAR-CON, exhibit better performances for intermediate threshold values between 20

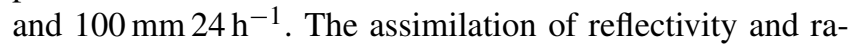
dial velocity reduces the gap between 4D-Var and 3D-Var methods, limited to low-intermediate thresholds but, on the other hand, improves the prediction of precipitation peaks due to convective phenomena. However, the addition of radial velocity seems to have a negative impact compared to radar reflectivity and conventional observations. In this respect, a future study shall be devoted to assess the goodness of the radial velocity data.

Nevertheless, all simulations carried out show an underestimation of effective rainfall over Gran Sasso area and along the Central-Northern Abruzzo coast and, conversely, an overestimation over Sibillini area: therefore, both variational methods fail in capturing the small-scale rainfall variability. In order to clarify this aspect and to provide a detailed analysis of precipitation pattern, we will apply a spatial verification method to the rainfall field (Davis et al., 2006). Moreover, an analysis of the time evolution of the skill score of the hourly precipitation will be done to the aim of investigating improvement during the spin-up time of the model. Finally, the addition of other cases study could be useful to strengthen the statistical analysis and understand if 4D-Var enhancements depend on the synoptic configuration.

Data availability. The rainfall data used in this work can be accessed through the DEWETRA platform of the Italian Civil Protection Department after authentication (http://www.protezionecivile. gov.it). Radar data are provided by the Centro Funzionale of the Abruzzo region.

Competing interests. The authors declare that they have no conflict of interest.

Special issue statement. This article is part of the special issue "16th EMS Annual Meeting \& 11th European Conference on Ap- plied Climatology (ECAC)". It is a result of the 16th EMS Annual Meeting \& 11th European Conference on Applied Climatology (ECAC), Trieste, Italy, 12-16 September 2016.

Edited by: Tomas Halenka

Reviewed by: two anonymous referees

\section{References}

Barker, D. M., Huang, W., Guo, Y.-R., Bourgeois, A., and Xiao, Q.: A Three-Dimensional Variational (3DVAR) data assimilation system for use with MM5: Implementation and initial results, Mon. Weather Rev., 132, 897-914, 2004.

Brown, B. G., Gotway, J. H., Bullock, R., Gilleland, E., Fowler, T., Ahijevych, D., and Jensen, T.: The Model Evaluation Tools (MET): Community tools for forecast evaluation, in: Preprints, 25th Conf. on International Interactive Information and Processing Systems (IIPS) for Meteorology, Oceanography, and Hydrology, Phoenix, AZ, Amer. Meteor. Soc. A, 9, 6, 2009.

Chu, K., Xiao, Q., and Liu, C.: Experiments of the WRF three/four-dimensional variational (3/4DVAR) data assimilation in the forecasting of Antarctic cyclones, Meteorol. Atmos. Phys., 120, 145-156, https://doi.org/10.1007/s00703-013-0243-y, 2013.

Davis, C., Brown, B., and Bullock, R.: Object-based verification of precipitation forecasts. Part I: methodology and application to mesoscale rain areas, Mon. Weather Rev., 134, 1772-1784, 2006.

Ducrocq, V., Braud, I., Davolio, S., Ferretti, R., Flamant, C., Jansa, A., Kalthoff, N., Richard, E., Taupier-Letage, I., Ayral, P., Belamari, S., Berne, A., Borga, M., Boudevillain B., Bock, O., Boichard, J., Bouin, M., Bousquet, O., Bouvier, C., Chiggiato, J., Cimini, D., Corsmeier, U., Coppola, L., Cocquerez, P., Defer, E., Delanoë, J., Di Girolamo, P., Doerenbecher, A., Drobinski, P., Dufournet, Y., Fourrié, N., Gourley, J., Labatut, L., Lambert, D., Le Coz, J., Marzano, F. S., Molinié, G., Montani, A., Nord, G., Nuret, M., Ramage, K., Rison, W., Roussot, O., Said, F., Schwarzenboeck, A., Testor, P., Van Baelen, J., Vincendon, B., Aran, M., and Tamayo, J.: HyMeX-SOP1: The field campaign dedicated to heavy precipitation and flash flooding in the Northwestern Mediterranean, B. Am. Meteorol. Soc., 95, 1083-1100, https://doi.org/10.1175/BAMS-D-12-00244.1, 2014.

Errico, R. M.: What is an adjoint method?, B. Am. Meteorol. Soc., 78, 2577-2591, 1997.

Errico, R. M. and Reader K. D.: An examination of the accuracy of the linearization of a mesoscale model with moist physics, Q. J. Roy. Meteor. Soc., 125, 169-195, 1999.

Errico, R. M., Vukicevic, T., and Reader, K.: Examination of the accuracy of a tangent linear model, Tellus, 45A, 462-477, 1993.

Ferretti, R., Pichelli, E., Gentile, S., Maiello, I., Cimini, D., Davolio, S., Miglietta, M. M., Panegrossi, G., Baldini, L., Pasi, F., Marzano, F. S., Zinzi, A., Mariani, S., Casaioli, M., Bartolini, G., Loglisci, N., Montani, A., Marsigli, C., Manzato, A., Pucillo, A., Ferrario, M. E., Colaiuda, V., and Rotunno, R.: Overview of the first HyMeX Special Observation Period over Italy: observations and model results, Hydrol. Earth Syst. Sci., 18, 1953-1977, https://doi.org/10.5194/hess-18-1953-2014, 2014.

Fulton, R. A., Breidenbach, J. P., Seo, D., Miller, D., and O'Bannon, T.: The WSR-88D rainfall algorithm, Weather Forecast., 13, 377-395, 1998. 
Hu, M., Xue, M., and Brewster, K.: 3DVAR and cloud analysis with WSR-88D level-II data for the prediction of the Fort Worth, Texas, tornadic thunderstorms. Part I: Cloud analysis and its impact, Mon. Weather Rev., 134, 675-698, 2006.

Huang, X. Y., Xiao, Q., Barker, D. M., Zhang, X., Michalakes, J., Huang, W., Henderson, T., Bray, J., Chen, Y., Ma, Z., Dudhia, J., Guo, Y., Zhang, X., Won, D. J., Lin H. C., and Kuo Y. H.: Fourdimensional variational data assimilation for WRF: formulation and preliminary results, Mon. Weather Rev., 137, 299-314, 2009.

Janjić, Z. I.: Non singular implementation of the Mellor-Yamada level 2.5 scheme in the NCEP Meso model, NCEP office note, 437, 61, 2002.

Kain, J. S.: The Kain-Fritsch convective parameterization: an update, J. Appl. Meteorol. 43, 170-181, 2004.

Liu, J., Bray, M., and Han, D.: Exploring the effect of data assimilation by WRF-3DVar for numerical rainfall prediction with different types of storm events, Hydrol. Process., 27, 3627-3640, https://doi.org/10.1002/hyp.9488, 2013.

Maiello, I., Ferretti, R., Gentile, S., Montopoli, M., Picciotti, E., Marzano, F. S., and Faccani, C.: Impact of radar data assimilation for the simulation of a heavy rainfall case in central Italy using WRF-3DVAR, Atmos. Meas. Tech., 7, 2919-2935, https://doi.org/10.5194/amt-7-2919-2014, 2014.

Mellor, G. L. and Yamada, T.: Development of a turbulence closure model for geophysical fluid problems, Rev. Geophys., 20, 851$875,1982$.

Picciotti, E., Montopoli, M., Gallese, B., Cimoroni, A., Ferrauto, G., Ronzitti, L., Mancini, G., Volpi, A., Sabatini, F., Bernardini, L., and Marzano, F. S.: Rainfall mapping in complex orography from C-band RADAR at Mt. Midia in Central Italy: data synergy and adaptive algorithms, Proceeding of ERAD 2006, Barcelona, Spain, 341-344, 2006.
Skamarock, W. C., Klemp, J. B., Dudhia, J., Gill, D. O., Barker, D. M., Duda, M. G., Huang, X. Y., Wang, W., and Powers, J. G.: A description of the Advanced Research WRF Version 3, NCAR Technical Note NCAR/TN-475+STR, 2008.

Sun, J. and Crook N. A.: Dynamical and microphysical retrieval from Doppler radar observations using a cloud model and its adjoint. Part I: Model development and simulated data experiments. J. Atmos. Sci., 54, 1642-1661, https://doi.org/10.1175/15200469(1997)054<1642:DAMRFD>2.0.CO;2, 1997.

Sun, J. and Wang, H.: Radar data assimilation with WRF 4DVar. Part II: comparison with 3D-Var for a squall line over the US Great Plains, Mon. Weather Rev., 11, 2245-2264, https://doi.org/10.1175/MWR-D-12-00169.1, 2013.

Sun, J., Xue, M., Wilson, J. W., Zawadzki, I., Ballard, S. P., OnvleeHooimeyer, J., Joe, P., Barker, D. M., Li, P-W., Golding, B., Xu, M., and Pinto, J.: Use of NWP for nowcasting convective precipitation, Recent Progress and Challenges, BAMS, 95, 409-426, https://doi.org/10.1175/BAMS-D-11-00263.1, 2014.

Thompson, G., Field, P. R., Rasmussen, R. M., and Hall, W. D.: Explicit forecast of winter precipitation using an improved bulk microphysics scheme. Part II: Implementation of a new snow parameterization, Mon. Weather Rev., 136, 5095-5115, 2008.

Wang, H., Sun, J., Zhang, X., Huang, X., and Auligne, T.: Radar data assimilation with WRF 4D-Var. Part I: system development and preliminary testing, Mon. Weather Rev., 141, 2224-2244, 2013.

Wilks, D. S.: Statistical Methods in the Atmospheric Sciences, 2nd Edn., Academic Press, 2006.

Xiao, Q., Kuo, Y.-H., Sun, J., and Lee, W.-C.: Assimilation of Doppler RADAR Observations with a Regional 3DVAR System: Impact of Doppler Velocities on Forecasts of a Heavy Rainfall Case, J. Appl. Meteor., 44, 768-788, 2005. 